http://dx.doi.org/10.30681/23588403v12i01240257

\title{
AS POTENCIALIDADES DO LIVRO DIDÁTICO PARA O LETRAMENTO CRÍTICO EM LÍNGUA INGLESA: UM OLHAR SOBRE O LIVRO ALIVE HIGH
}

\author{
Data de recebimento: $05 / 10 / 2018$ \\ Aceite: 16/11/2018
}

\author{
Joelinton Fernando de Freitas (UNEMAT) ${ }^{1}$
}

\begin{abstract}
Resumo: A presente pesquisa buscou investigar se os gêneros textuais presentes em três unidades do livro didático Alive High estão em consonância com o letramento crítico, bem como, se atendem ao disposto na legislação pertinente ao livro didático nas bases governamentais destinada ao ensino-aprendizagem para o ensino médio. A natureza da pesquisa é qualitativa/bibliográfica na qual coletamos e analisamos os dados pelo viés documental. Os resultados obtidos foram de que o livro apresentou, nas três unidades analisadas, gêneros textuais com potencial para o letramento crítico em língua inglesa e temas que podem ser considerados adequados e interessantes para a faixa etária dos estudantes do ensino médio. Através de tópicos de pré e pós-leitura os autores conseguiram construir questionamentos mais elaborados e que podem instigar discussões dos pontos de vistas dos alunos em sala de aula para se posicionarem criticamente, além de instigar a produção de inferências de compreensão detalhada e global do texto
\end{abstract}

Palavras-chave: Livro Didático. Letramento Crítico. Língua Inglesa.

\begin{abstract}
The present research sought to investigate whether the textual genres present in three units of the textbook Alive High are in line with the critical literacy,as well as if they meet the provisions of the legislation relevant to the textbook in the government bases that are intended for high school. The nature of the research is qualitative and bibliographical in which we collect and analyzed the data through the documentary bias. The results gathered were that, the textbook presented, in three units analyzed, textual genres with potential for critical literacy in English Language and its themes may be considered appropriate and interesting for the age group of the students of the first year of High School. Through topics of pre-reading and post-reading, the authors managed to build more elaborate questions that may instigate discussions of the student's viewpoint in the classroom to position themselves critically, in addition to instigate the production of detailed and global comprehension inferences from the text.
\end{abstract}

Keywords: Textbook; Critical Literacy; English Language.

\section{Introdução}

O presente artigo tem como objeto de estudo o Livro Didático (LD) de Língua Inglesa (LI) “Alive High" volume 1, destinado ao ensino médio. Sendo assim, discutiremos a respeito

\footnotetext{
${ }^{1}$ Graduado em Letras Português e Inglês pela UNEMAT/Núcleo de Sorriso. Cursando especialização em Docência no Ensino Superior IFMT/Sorriso. E-mail: joelintonfreitas@gmail.com
} 
da importância desse instrumento, sua função, utilização pedagógica e outras considerações que julgamos relevantes para a pesquisa. ${ }^{2}$

Além disso, analisaremos gêneros textuais e seus respectivos exercícios de compreensão de leitura presentes em três unidades das seções "Let's read" desse LD, a fim de descobrir se estão em consonância com os multiletramentos críticos, bem como, se atendem ao disposto na legislação pertinente ao LD nas bases governamentais destinada ao ensinoaprendizagem para o ensino médio.

É inegável que o LD se tornou com o passar do tempo, um dos principais instrumentos de apoio e insumo pedagógico em sala de aula. Algumas pesquisas vêm sendo realizadas sobre o LD, analisando os seus mais variados aspectos tais como o pedagógico, o político, o econômico e o cultural. Estas pesquisas geram polêmicas, pois o LD trata-se de uma ferramenta que desperta olhares e opiniões distintas por parte de pesquisadores, professores e alunos.

No ensino-aprendizagem de línguas o LD tornou-se um instrumento pedagógico muito presente. Muitas vezes, tem o foco central na aula e dependendo de como é utilizado, pode passar a ser seguido rigorosamente. No entanto, segundo Xavier e Urio (2006), há professores que preferem utilizá-lo apenas como referencial no preparo de suas aulas sem segui-lo literalmente.

Com isso, um ou mais LD são examinados para organizar as atividades de ensino. "Há ainda professores que não recorrem aos LD como material norteador, e dessa forma preferem produzir suas próprias atividades com base em textos de revistas e jornais ou em outros materiais inspiradores que possam ter fins didáticos”. (XAVIER e URIO, 2006, p. 30).

Mesmo sendo um dos instrumentos utilizados em sala de aula a muito tempo, no âmbito púbico, o LD de inglês passou a fazer parte do Programa Nacional do Livro Didático (PNLD) apenas em 2011. A importância dessa iniciativa está registrada no Guia de Livros Didáticos de Língua Estrangeira Moderna do PNLD (2011, p.9) que considera o LD como um importante instrumento acessível as escolas públicas brasileiras e reflete a importância dada a formação dos estudantes. De acordo com o programa, ter LD de Língua Estrangeira (LE) na

\footnotetext{
${ }^{2}$ Agradeço a professora Dra. Olandina Della Justina pela orientação da pesquisa, na graduação, que deu origem a este artigo.
} 


\section{Revista de Estudos Acadêmicos de Letras}

escola, significa um grande avanço para o ensino público brasileiro. Com essa atitude, os LD de LE despertaram interesse por parte de pesquisadores da área da Linguística Aplicada.

Iniciaremos o artigo discutindo a questão dos novos letramentos e o LC, o LD e a docência, e a transposição dos gêneros textuais para o LD. Por fim, examinaremos algumas unidades do livro selecionado a fim de refletir em que medidas ele contribuiu para um ensino de mais crítico e relevante para os dias atuais.

\section{OS NOVOS LETRAMENTOS}

Os novos letramentos surgem com força a partir das novas formas de linguagem, comunicação e nos recursos tecnológicos que estão presentes em nosso dia a dia. Vivemos em um mundo globalizado e em constante mudança. Segundo Xavier (2015): Na atual sociedade globalizada e digitalizada, ser letrado, ou seja, ter domínio apenas sobre práticas de leitura e escrita já não é suficiente.

O cidadão, hoje, precisa dominar várias outras habilidades para não apenas usufruir dos benefícios da vida moderna, mas também participar ativamente da comunidade na qual está inserido, fazendo intervenções construtivas e contribuindo de maneira ativa para o avanço da mesma. (XAVIER, 2015, p. 3)

Pesquisadores já falam em multiletramentos, afinal diversas são as formas pelas quais a linguagem se manifesta em nossas vidas. Existe uma grande disparidade de discussões em torno do conceito de letramento, pois o mesmo, muitas vezes. É confundido com o termo alfabetização.

Antes de embarcarmos nas definições sobre o letramento, faz-se necessário esclarecer sobre a diferença do termo alfabetização e letramento para uma melhor compreensão do rumo desta pesquisa.

O termo letramento é uma tradução para o português da palavra inglesa “literacy” que pode ser traduzida como a condição de ser letrado. Um indivíduo alfabetizado não é necessariamente um indivíduo letrado, o indivíduo alfabetizado sabe decodificar os códigos, as letras, sabendo ler e escrever. No entanto, um indivíduo letrado é aquele que utiliza sua capacidade de leitura e escrita para participar de práticas sociais.

De acordo com Soares (2000): À medida que o analfabetismo vai sendo superado na sociedade, surge uma nova necessidade: a de incorporar e se apropriar das práticas de leitura e 
escrita, usá-las socialmente e responder adequadamente às demandas sociais de sua utilização. Foi então que vieram à tona discussões sobre o letramento, a fim de tornar as aulas de línguas mais significativas para o aluno, ao aproximar a escola à vida, a língua à prática social (SOARES, 2000 apud ORLANDO e FERREIRA, 2012, p. 415).

Para Xavier (2012), existem benefícios trazidos pelas práticas socioculturais que o sujeito alfabetizado ainda não experimentou, os quais são:

a) compreender textos mais elaborados, e que exigem uma compreensão mais profunda cujos enunciados contam com informações implícitas, pressupostas ou subentendidas;

b) elaborar com frequência relatórios detalhados de trabalho;

c) escrever textos argumentativos para defender o seu ponto de vista de modo claro e convincente;

d) descrever com precisão e astúcia pessoas e ambientes vistos ou imaginados por ele, entre outros usos mais complexos que podem ser feitos com a escrita.

Isso quer dizer que o indivíduo letrado vai além da decodificação de letras e símbolos (como é o caso do sujeito alfabetizado), ele consegue de fato interpretar, fazer ligações dos textos com sua vida cotidiana percebendo semelhanças e diferenças, além de demonstrar fortemente seus argumentos embasados e sólidos defendendo pontos de vista além de pensar e agir criticamente.

Em outras palavras, segundo Borba e Aragão (2012, p. 229), a oposição entre alfabetização e letramento está principalmente na noção de prática social. Essa diferença se definiu ao se perceber que, da averiguação da capacidade ou habilidade de escrever o próprio nome, passou-se à averiguação da capacidade de uso da leitura e da escrita para uma prática social.

O que se confirma, segundo Barton (1994):

Antes de constituir um conjunto de habilidades intelectuais, o letramento é uma prática cultural, sócio e historicamente estabelecida, que permite ao indivíduo apoderar-se das suas vantagens e assim participar efetivamente e decidir, como cidadão do seu tempo, os destinos da comunidade à qual pertence e as tradições, hábitos e costumes com os quais se identifica. (BARTON, 1994 apud XAVIER, 2012, p.2) 
Conforme Borba e Aragão (2012 apud Soares, 2004), o letramento abrange um conjunto de fatores que variam de aptidões e conhecimentos individuais a práticas sociais e competências funcionais e, também, a valores ideológicos e fins políticos. Por isso, a ideia de que a apropriação da escrita pode trazer consequências de ordem social, política, cultural, econômica e linguística, quer para o grupo social em que seja introduzida, quer para o indivíduo que aprende a usá-la.

Dialogando com Mattos (2011, p.103), entendemos que a questão dos novos letramentos compreende uma noção de linguagem como prática social e também o entendimento de que é necessário proporcionar e instigar o desenvolvimento do senso crítico dos cidadãos/alunos, fazendo que eles se permitam questionar, analisar e contestar as relações de poder existentes, com vistas a provocar mudança social.

Nas palavras de Orlando e Ferreira (2012):

\begin{abstract}
Nesse sentido, o contexto atual em que se insere o ensino exige de nós, professores (as), (re) pensar sempre quais caminhos percorrer para garantir a aprendizagem de uma língua de modo plural. Nesse contexto, com o uso mais intenso das novas tecnologias, dando conta dos complexos usos de linguagem, há a demanda de um ensino de línguas que parte de um posicionamento mais crítico frente à realidade, aos conteúdos dados pelos materiais de ensino, às informações trazidas à sala de aula por alunos(as) e professores(as), isto é, de uma prática pedagógica de ordem mais colaborativa e reflexiva, trazendo à tona conceitos como heterogeneidade da linguagem e da cultura, comunidades de prática, multiletramentos. (ORLANDO E FERREIRA, 2012, p. 416)
\end{abstract}

Nessa direção, essa pesquisa preocupa-se em analisar o LD perante uma dessas vertentes dos novos letramentos, o LC. Dialogando com teóricos sobre algumas definições encontradas para esse termo. Sendo assim, trataremos sobre esse assunto no próximo tópico.

\title{
O LIVRO DIDÁTICO E O LETRAMENTO CRÍTICO
}

Após a publicação de documentos oficiais em nosso país como PCN e OCEM, criouse uma nova perspectiva sobre o ensino de línguas na Educação Básica que visa desenvolver e focalizar a leitura, a prática escrita e a comunicação oral contextualizadas. Para que o aluno seja visto como um cidadão que atuará em sociedade, além de reafirmar a relevância da noção de cidadania, e contemplação dos novos letramentos ou LC.

Mas o que se define ou conceitua por LC no ensino-aprendizagem de LI? Diversos autores dialogam sobre um ensino com foco no despertar crítico dos alunos. As OCEM 
entendem o LC como um conjunto de teorias que busca promover a construção de um questionamento relevante por parte dos alunos, visando sua transformação social.

Conforme salienta Monte Mór (2013 apud ROCHA, 2014, p.9), a necessidade de uma formação educacional crítica e do desenvolvimento de cidadãos críticos por meio dessa formação é amplamente reconhecida e defendida na atualidade, sendo o conceito polissêmico e compreendido de diferentes maneiras.

Advogamos que os LDs mesmo os de LE, precisam trazer em sua essência a preocupação em trabalhar e promover o despertar crítico dos alunos. Suas propostas de trabalho devem ater-se a essa questão, fazendo com que a sala de aula se torne um lugar onde os alunos sintam-se à vontade para analisar, expor a criticidade que carregam internamente, deixar o aluno ter voz e em um próximo passo usá-la no meio social em que convive.

Segundo Monte-Mór (2014):

\begin{abstract}
O termo 'crítico' pode ser postulado de duas maneiras distintas, baseadas em Barthes (1999) e Gikandi (2005). A primeira a partir do uso do termo 'criticism' - em um sentido acadêmico, seria resultado da escolaridade -; e um segundo seria o termo 'critique', - em um sentido ideológico, ou seja, a capacidade crítica do sujeito não se atrelar aos níveis de escolarização a qual foi submetido, indicando assim a visão de que há pensadores críticos e pensadores comuns. (MONTE-MÓR, 2014 apud XAVIER, 2015, p. 125)
\end{abstract}

Nas aulas de LI na escola, pode-se orientar e sensibilizar o aluno em relação ao mundo multilíngue e diversidades culturais em que vive, além de despertar a conscientização acerca de diferenças culturais e levando-o a respeitar mais o outro e conhecer melhor a si mesmo, uma vez que é por meio do olhar do outro que aprendemos a nos conhecer melhor (TILIO, 2012). O LD pode ser um instrumento que auxilie nesse processo e apresentar conteúdos significativos que despertem e promovam olhares críticos a partir dos gêneros que circulam em diferentes contextos globais.

McLaughlin e DeVoogd (2004, p. 14 apud MATTOS, 2011, p. 43) afirmam que o letramento crítico considera "os leitores como participantes ativos no processo de leitura", permitindo que os leitores deixem de "aceitar passivamente a mensagem do texto para questionar, examinar e desafiar as relações de poder que existem entre leitores e autores".

De acordo com Arantes (2008):

Qual seria então, a função primordial do livro didático, senão a de criar oportunidades através de suas atividades para que os alunos possam entrar em 
contato com situações de uso social da língua que os levem a desenvolver a habilidade de estabelecer estes elos coesivos, inferir sentido, ou seja, ler textos escritos autênticos que circulam socialmente, sendo capaz de ter acesso informação e de refletir criticamente sobre ela? (ARANTES, 2008 apud LIMA, 2012, p. 3)

Unindo o conceito de LC das OCEM (BRASIL, 2006, p. 117), notamos que os LDs também podem continuar trabalhando a compreensão geral, dos pontos principais e as informações detalhadas do texto, assim como os elementos linguísticos-textuais oferecidos pelos textos selecionados, e que esses contribuem para a compreensão e a construção de sentidos.

Mas para que de fato ocorra o LC deve-se haver uma ampliação e uma definição desse trabalho de leitura no que se refere à expectativa de desenvolvimento crítico dos alunos, afinal nenhum texto é neutro, e nas aulas de LE deve haver uma educação crítica com expansão de pontos de vista, indo além do que se lê.

No item seguinte, abordaremos sobre a transposição dos gêneros textuais circulantes em sociedade para utilização em LD. Pois o trabalho com gêneros textuais no ensino de línguas vem sendo alvo de diversas pesquisas em Linguística Aplicada e aparecem em documentos como PCN e OCEM.

\section{OS GÊNEROS TEXTUAIS E A TRANSPOSIÇÃO PARA O LIVRO DIDÁTICO}

Neste ponto, explicaremos os conceitos de gêneros textuais, para que assim se compreenda os rumos deste trabalho. E ademais, trataremos da transposição dos gêneros textuais para o LD.

Em nossa sociedade contemporânea, se faz necessário que as pessoas desenvolvam habilidades comunicativas para que interajam de maneira mais crítica e participativa. Com isso, entendemos que na perspectiva educacional, deve-se investir em estudos sobre o uso da linguagem em variados contextos específicos.

Dessa forma, é necessário que o ensino-aprendizagem da linguagem, possa promover a compreensão de como a língua se articula na ação humana em nossa sociedade. Uma das formas encontradas, é o uso dos gêneros textuais variados e circulantes em nosso meio para demonstrar os usos reais da linguagem.

De acordo com Dell'Isola (2009):

Gêneros textuais são manifestações sociais constituídas de elementos verbais e/ou não-verbais intencionalmente selecionados e organizados para exercer uma atividade sociointerativa, de modo a permitir aos interlocutores, a depreensão de sentido, em decorrência da ativação de processos e estratégias de ordem cognitiva, e ação de 
acordo com a situação e as práticas socioculturais de uso. Não são apenas formas, são atividades submetidas a critérios de êxito. (DELL'ISOLA, 2009, p.100)

Segundo Marcuschi (2008), podemos compreender, portanto os gêneros textuais como produtos culturais construídos historicamente pelos seres humanos.

Os gêneros possuem uma estrutura fixa para cada fim para o qual são elaborados, em cada esfera social em que o homem atua encontramos uma gama de textos que foram sendo criados à medida que seu uso se tornou necessário para $o$ estabelecimento da comunicação entre os sujeitos (SILVA; SUASSUNA, 2014, p.202).

Os gêneros, estão presentes em nossa vida e os utilizamos para conseguir alcançar determinados fins comunicativos. "Na medida em que os contextos sociais e as atividades humanas são inúmeros e cada esfera social tem seu repertório de gêneros próprios, podemos afirmar que existe uma grande diversidade de gêneros diferentes entre si na sociedade" (SILVA; SUASSUNA, 2014). Dialogando com BAKHTIN (2003), entendemos que cada domínio de utilização da língua elabora seus tipos relativamente estáveis de enunciados, e dessa forma denominamos os gêneros do discurso.

Segundo Dell'Isola:

Por meio da exploração de gêneros textuais é possível realizar um trabalho eficiente, partindo da discussão sobre relações sociais, identidades e formas de conhecimento, veiculadas por meio de textos em variadas circunstâncias interação, de determinações socioistóricas e da interação entre autor-texto-contexto-leitor e da observação da variedade de possibilidades de organização textual. (DELL'ISOLA, 2009, p.100)

Mas, e quanto a transposição de gêneros textuais para os LD de LE? Os gêneros textuais, como qualquer outro conhecimento a ser ensinado na sala de aula, também são submetidos a um processo de escolarização. Segundo Marcuschi (2006), na escola há uma transposição didática, na qual o gênero que circula socialmente abandona suas práticas de origem e chega à sala de aula, colocando-se a serviço do ensino e da aprendizagem.

Dessa forma, ao incorporar-se um texto ou qualquer outro gênero textual tais como: cartas, e-mails, receitas, artigos etc, eles sofrem uma transmutação segundo Bakthin (2003). Quando é inserido e um contexto pedagógico, para ensinar aspectos da língua em uso, e transposto para o LD, o gênero textual não fica mais vinculado ao contexto pelo qual foi produzido, e passa a ter o objetivo de ensinar.

É importante que o LD ofereça plenas condições para o aprendizado da língua alvo por meio de atividades que viabilizem a construção de sentido de modo que o aluno possa se familiarizar com textos que circulam em diversos cenários onde essa língua é falada e possa explorá-las. (DELL'ISOLLA, 2009, p.102) 


\section{Revista de Estudos Acadêmicos de Letras}

Diante disso, inferimos que este conhecimento da língua alvo corrobora para o aluno criar condições de se expressar de maneira verbal (oral ou escrita). Desta maneira, percebemos que a inserção de variados gêneros textuais em um LD se faz necessário para o acesso à diversas práticas sociais da cultura da LE aprendida. Com isso, o aprendiz pode compreender o funcionamento de diferentes comunidades discursivas e as diferentes formas da língua em usa.

No tópico seguinte e para fins deste artigo, trataremos de analisar os gêneros textuais e exercícios de compreensão de leitura presentes na Part 1 (Express Yoursef) e Part 2 (Move your body) do livro, mais precisamente das unidades 1, 2 e 3 que tem como títulos What's your talent?, Street Art e You've got the movies respectivamente.

\section{ANÁLISE DOS GÊNEROS TEXTUAIS E ATIVIDADES DO LIVRO}

As figuras a seguir, se tratam dos gêneros textuais da primeira unidade bem como, as atividades de compreensão escrita.

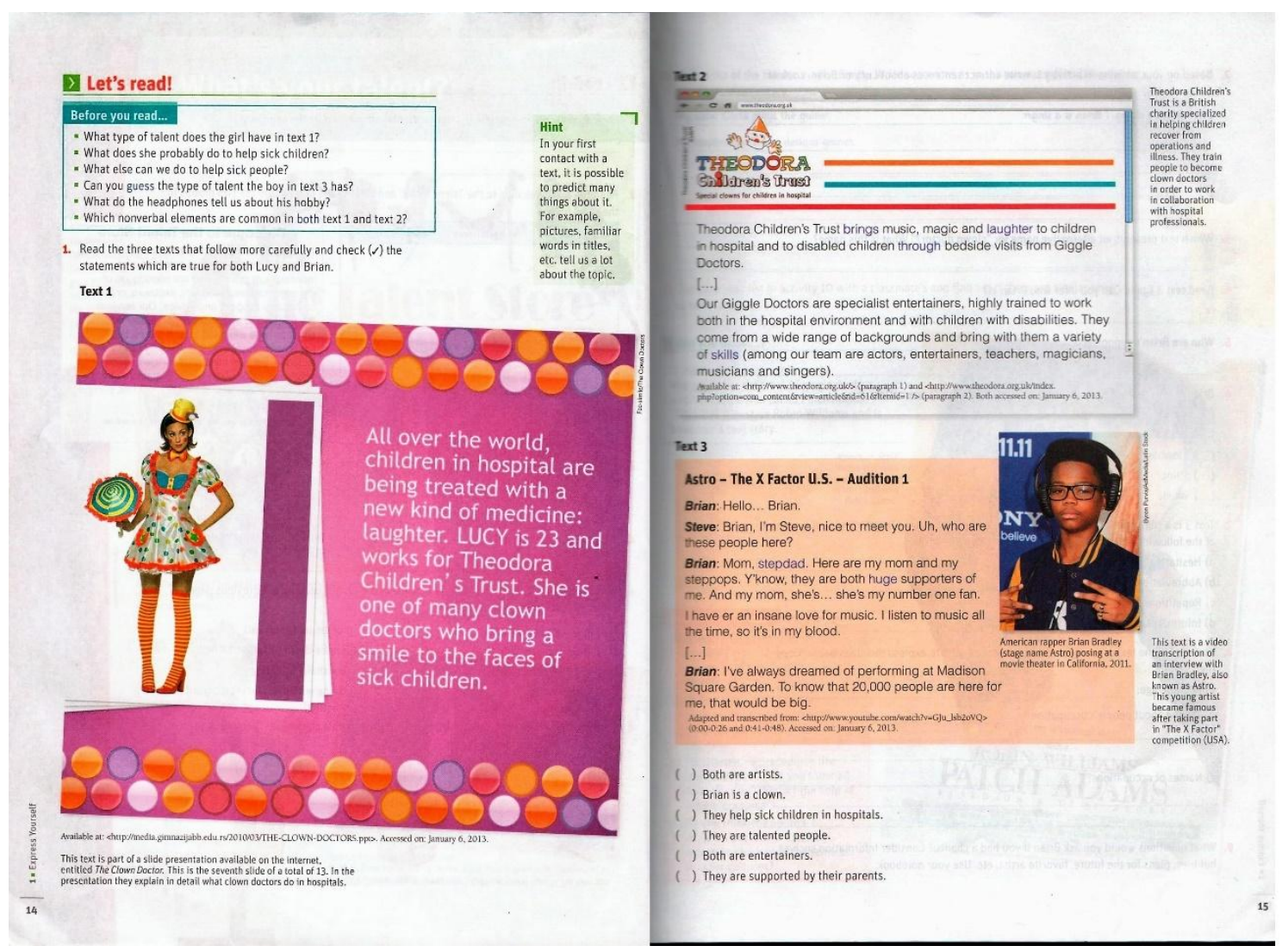

Figura 1: Imagem da apresentação de slide da instituição Theodora Children's Trust; Artigo on-line sobre a instituição de caridade Theodora Children's Trust e transcrição de vídeo do Youtube: entrevista com Brian Bradley

Fonte: Alive High. Volume 1 
O gênero textual Text 1 da figura 1 é um recorte de um slide que foi retirado de uma apresentação disponível na internet, no qual a personagem Lucy é dada como exemplo pois leva alegria às crianças internadas em hospitais, através de uma instituição de caridade.

A seguir, temos dois textos Text 2 e Text 3. O Text 2 conecta-se ao texto presente na figura 1, pois trata-se de um artigo on-line, o qual explica sobre a instituição de caridade "Theodora Children's Trust", que é especializada em ajudar crianças na recuperação de cirurgias e doenças. No Text 3, temos a transcrição de um vídeo disponível no site youtube, e o personagem principal é um adolescente que faz uma audição em um programa de talentos nos EUA.

Todos os textos presentes nestas duas páginas foram transpostos da Internet para o LD, percebermos um ponto positivo nisso pois são textos circulantes no meio social e que são de fácil acesso. No entanto, ao fazer a transcrição de um vídeo do Youtube por exemplo, o texto acaba perdendo sua multimodalidade. De acordo com umas das autoras do livro Paiva (2014, p. 354) "Trabalhar com textos autênticos é outro desafio, pois ao retirar o texto, ou trechos dele de seu contexto de circulação, ou mesmo ao alterar sua formatação, estamos, inevitavelmente, interferindo em sua autenticidade. ”

Para Tomlinson um texto autêntico é:

Um texto que não foi escrito ou falado com o objetivo de ensinar línguas. Um artigo de jornal, um rock, um livro, uma entrevista de rádio, instruções de como jogar determinado jogo e um tradicional conto de fadas são exemplos de textos autênticos. Uma história escrita para exemplificar o uso de reported speech, um diálogo roteirizado para exemplificar os modos de convidar e uma versão linguisticamente simplificada de um livro não constituiriam textos autênticos. (TOMLINSON, 2011 apud DELFINO, 2016, p. 57)

Parafraseando Nassim (2013), o uso de textos autênticos apresenta muitas vantagens pois incluem a motivação do aluno, que percebe que está em contato com amostras reais da língua; intrinsicamente ligado a isso está a confiabilidade do professor na capacidade do aluno para lidar com os textos autênticos; e outro benefício é a relação com a cultura dos países falantes da língua já que sempre está presente nos textos e pode ser observada e discutida.

De acordo com os PCN:

Nessa linha de pensamento, deixa de ter sentido o ensino de línguas que objetiva apenas o conhecimento metalinguístico e o domínio consciente de regras gramaticais que permitem, quando muito, alcançar resultados puramente medianos em exames escritos. Esse tipo de ensino, que acaba por tornar-se uma simples repetição, ano após ano, dos mesmos conteúdos, cede lugar, na perspectiva atual, a uma modalidade de curso que tem como princípio geral levar o aluno a comunicar-se de maneira adequada em diferentes situações da vida cotidiana. (PCN LINGUAGENS/ENSINO MÉDIO, 2000, p.26) 


\section{Revista de Estudos Acadêmicos de Letras}

Os exercícios que seguem os textos presentes na figura 2 a seguir, foram elaborados de maneira que os alunos retirem informações do texto e copiem como respostas, ou seja, informações de cunho linguístico e que são encontradas na maioria dos LDs disponíveis atualmente no mercado editorial. Portanto, mesmo que os textos mostrem um potencial para leitura crítica, alguns dos exercícios deixam a desejar.

Figura 2: Exercícios de compreensão de leitura. Fonte: Alive High volume 1
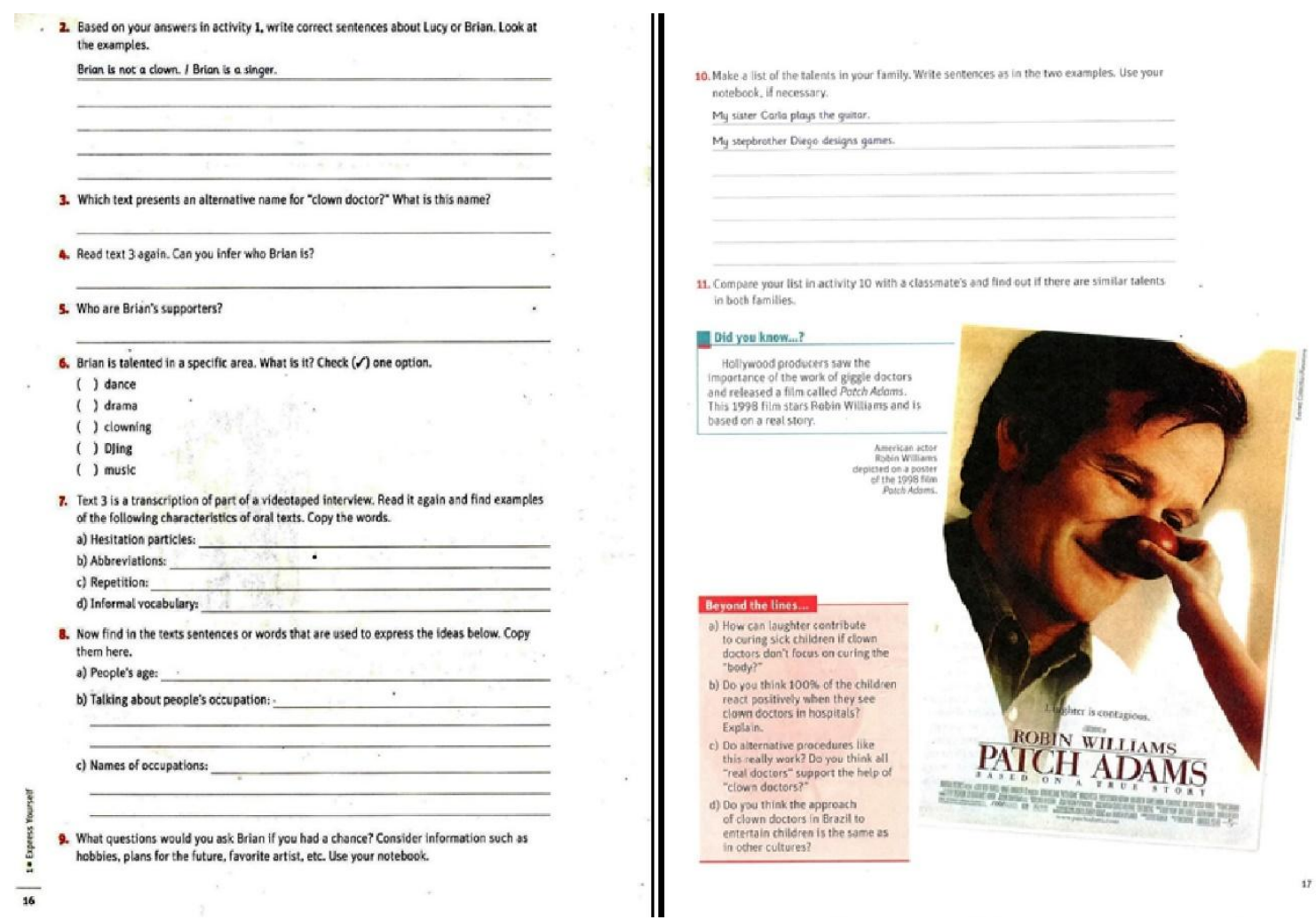

Dessa forma, entendemos que seja necessário que a leitura do texto instigue uma leitura mais crítica por parte dos alunos. Levando em considerações o contexto de onde partiram os textos, as finalidades de cada gênero textual, as mensagens trazidas pelos autores e inferirem sobre os contratos do texto com relação as suas próprias realidades.

No entanto, ao final dos exercícios percebemos questionamentos através do tópico Beyond the lines que podem inferir para discussão e tomada de posição crítica dos estudantes em sala de aula. Dentre as perguntas estão:

- Como o riso pode contribuir na cura de crianças doentes, se os doutores palhaços não focam na cura do corpo?

- $\quad$ Você acha que $100 \%$ das crianças reagem positivamente quando eles veem os palhaços nos hospitais?

- Você acha que todos os "médicos reais" apoiam os "médicos palhaços"? 
- Você acha que a aproximação dos médicos palhaços para entreter crianças no Brasil é a mesma como em outras culturas?

Ao fazermos a leitura das OCEM e PCN, percebemos que o enfoque no LC não despreza o trabalho com leitura que envolve reconhecimento, decodificação e compreensão que se faz presente nos LD, mas o estende à interpretação e transposição social, de forma a fazer da atividade de leitura realmente uma prática social.

Ainda notamos uma certa tendência pela predominância de atividades que se prestem ao desenvolvimento das habilidades de integração de informação verbal e não-verbal e de localização de informação específica no texto escrito. Entretanto, percebe-se algum movimento em direção ao desenvolvimento das habilidades de inferência, já que as atividades do tópico Beyond the lines se propõem ao desenvolvimento de inferência com base no contexto, no conhecimento adquirido de regras gramaticais e no conhecimento prévio.

Para os PCN da área de Linguagens/LE:

Torna-se, pois, fundamental, conferir ao ensino escolar de Línguas Estrangeiras um caráter que, além de capacitar o aluno a compreender e a produzir enunciados corretos no novo idioma, propicie ao aprendiz a possibilidade de atingir um nível de competência linguística capaz de permitir-lhe acesso a informações de vários tipos, ao mesmo tempo em que contribua para a sua formação geral enquanto cidadão. (PCN, 2000, p.26)

Sabe-se, que o ensino de LI nas escolas e as atividades propostas nos LD muitas vezes adotam métodos que resultam em uma tipologia de atividades voltada principalmente para o conhecido preenchimento de lacunas. A partir da análise dos exercícios contidos em materiais didáticos questionamos se estes, ajudam na compreensão textual levando em consideração não só a língua como forma, mas também o contexto discursivo.

A partir da análise das figuras, notamos então, que os autores mesclam exercícios de cunho instrumental, ou seja, exercícios cujo a finalidade é identificar o assunto principal abordado no texto, criando uma estratégia de compreensão geral, para que os alunos se detenham a pequenos detalhes do vocabulário buscando compreender o sentido geral do texto. No entanto, os autores conseguiram através de um tópico de pré-leitura e também de pósleitura, introduzir perguntas de cunho mais elaborado e crítico.

Seguindo na análise, trataremos de analisar a figura 3 a seguir, que se trata de um artigo on-line sobre o tema grafite. O texto pode ser acessado no site TheSite.org, e de acordo com informações trazidas pelos autores em notas paralelas ao texto, este site é um guia online para a vida de adolescentes e de jovens adultos.

Percebemos que tanto em nosso país quanto em qualquer outro, esse tipo de arte traz discussões sobre sua legalidade por se tratar de uma arte de rua, e ainda é vista com maus 


\section{Revista de Estudos Acadêmicos de Letras}

olhos por muitas pessoas. O texto retirado de um site que tem como público alvo os adolescentes, traz informações e definições a respeito do termo e esclarece quais são as punições para quem for pego grafitando sem autorização no Reino Unido.

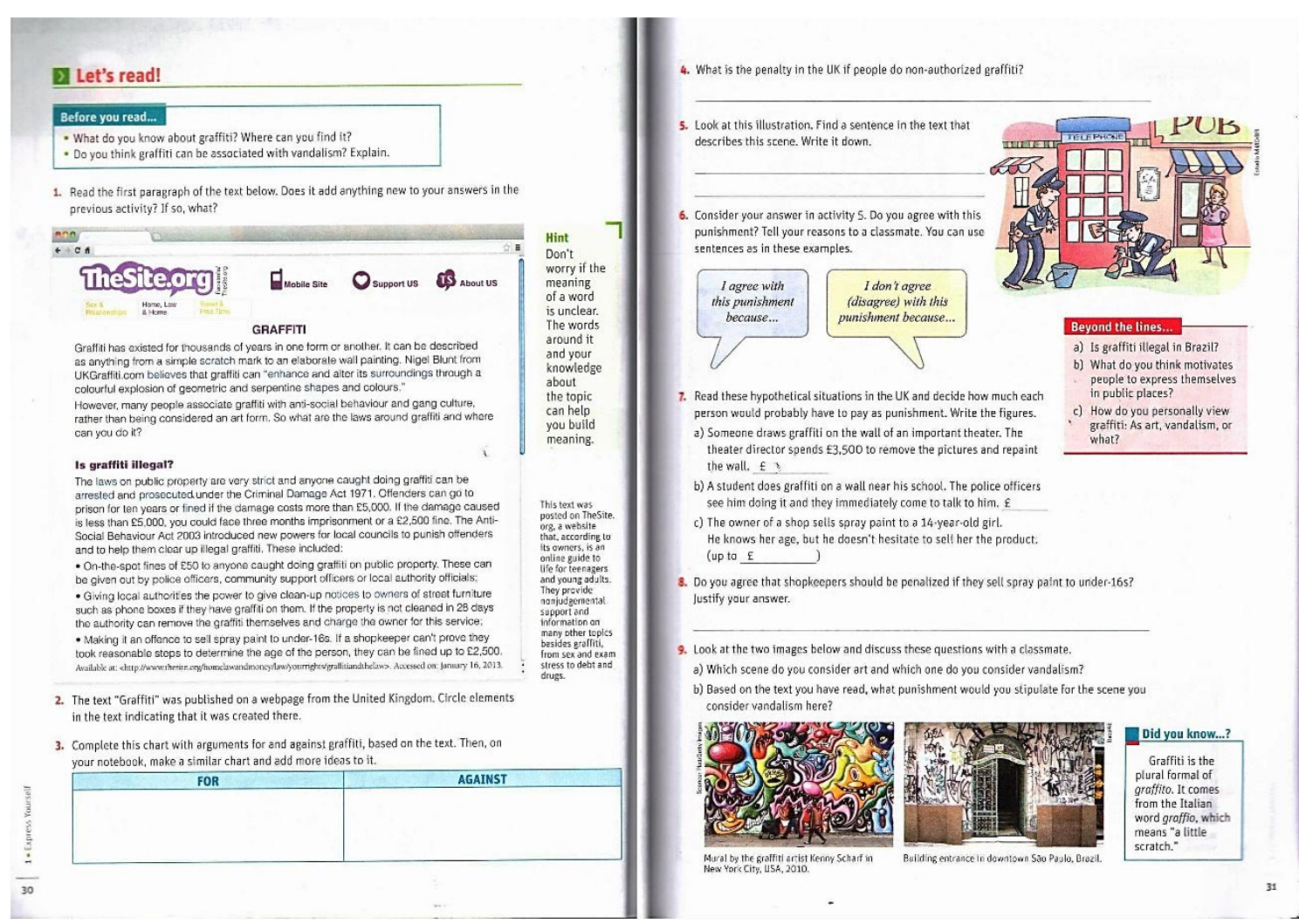

Figura 3: Artigo on-line sobre grafite e exercícios de compreensão de leitura. Fonte: Alive High volume 1

Ao analisarmos os exercícios, notamos novamente que foram elaborados para que os alunos busquem informações no texto e copiem em formas de repostas. No entanto, os autores preocuparam-se também em acrescentar perguntas que instigassem o debate dos alunos sobre ser contra ou a favor as punições relatadas no texto, e no exercício de número nove, duas imagens são contratadas para que os alunos considerem o que é arte (grafite) e o que é vandalismo na opinião deles, além de discutirem sobre quais seriam as punições que dariam aos que cometessem vandalismo.

Um ponto positivo elaborado pelos autores, foi a contextualização do texto para a realidade dos alunos brasileiros. Alguns questionamentos tinham como objetivo fazer com que os alunos pudessem contrastar o tema do gênero textual com a realidade no nosso país. Mais uma vez, esse tipo de pergunta foi trazido no tópico Beyond the lines. 
Analisando o texto e como os exercícios foram elaborados, notamos que o assunto tratado, pode se fazer interessante e de acordo com a faixa etária à qual o material se destina, adolescentes saindo do ensino fundamental e iniciando sua trajetória pelo ensino médio.

Ao analisarmos os gêneros, percebemos que são bem trabalhados tanto nos aspectos formais quanto nas sequências linguísticas e propósitos comunicativos. A coleção também apresenta temas atuais e sugere um projeto que deve ser desenvolvido em equipe no final de cada lição. Isso pode corroborar para o diálogo e as discussões na sala de aula.

Ao analisarmos os gêneros textuais da seção Let's read do LD Alive High, notamos que os autores se preocuparam em trazer textos autênticos e que podem apresentar-se atrativos para os adolescentes do ensino médio. Dessa forma, os autores trataram a leitura como uma prática sociocultural, atendendo aos pressupostos do LC apresentado nas OCEM e PCN, e tornando o LD como fonte de conteúdo atual e acessível aos alunos.

O LD se mostra então, como potencializador para o LC em LE. Mas por se tratar de um LD, em sala de aula, será sempre necessária adaptação aos diferentes contextos de ensino de LI nas escolas de nosso país.

\section{CONCLUSÃO}

Após analisarmos os dados coletados no LD Alive High volume 1 e dialogar com diversos teóricos que estudam os $\mathrm{LD}$, bem como o LC em LI, concluímos que o livro trouxe textos que podem potencializar o LC em LE. Os autores do LD tiveram cuidado e dispuseram de uma variedade de textos que circulam na sociedade e podem servir como base para discussões e aprendizados da língua em diversos contextos.

Podemos destacar também, que muitos dos textos trazem conteúdos atuais e que dialogam com a realidade de muitos adolescentes do ensino médio além de serem importantes para a formação cidadã. De acordo com as observações feitas no decorrer das unidades, percebemos que foram organizadas com uma combinação de textos e imagens que beneficiam discussões sobre temas pertinentes à vida social dos estudantes. Todos esses aspectos vão ao encontro da formação de um aluno-leitor mais crítico.

A partir da leitura das figuras, pudemos perceber que os textos abordam temas que podem ser familiares aos estudantes e aparece na coleção um repertório diversificado de gêneros textuais, que variam entre não verbais e verbo-visuais como, por exemplo: biografias, notícias, artigos, imagens, desenhos, pinturas, esculturas, pôsteres, folhetos, propagandas, capa de revista, previsão do tempo, etc. Que proporcionam uma maior ênfase aos gêneros que são acessíveis da web. 
O LD traz exercícios de interpretação de leitura mesclados entre a preocupação em pontos gramaticais para que os alunos copiem partes do texto, encontrem palavras relacionadas e a partir dos insumos linguísticos como imagens, palavras grifadas e excertos além de inferirem sobre qual o tema principal do gênero textual, mas notamos que os exercícios ficam contextualizados a fim de que os alunos compreendam e reflitam com maior facilidade sobre o que leram.

Sendo assim, este trabalho espera contribuir para acadêmicos e pesquisadores na área das linguagens, principalmente da Linguística Aplicada, além de professores de LE, pois ao analisarmos o LD, analisamos uma das ferramentas de ensino mais importantes que se faz presente nas salas de aula das escolas de nosso país.

\section{REFERÊNCIAS}

BRAGA, J; CARNEIRO, M; RACILAN, M; GOMES, R; VELLOSO, M. Alive High. v.1, São Paulo: SM, 2014. f.200.

Estética da criação verbal. 2. ed. São Paulo: Martins Fontes, 1997.

ARANTES, J. E. O livro didático de língua estrangeira: Atividades de compreensão e habilidades no processamento de textos na leitura. 2008. 99f. Dissertação (Mestrado em Linguística Aplicada) -Programa de Pós-Graduação em Estudos Linguísticos, Universidade Federal de Minas Gerais, Belo Horizonte, 2008.

BORBA, M. S. \& ARAGÃO, R. Multiletramentos: novos desafios e práticas de linguagem na formação de professores de inglês. Polifonia, v. 19, n. 25, p. 223-240, jan./jul., 2012.

BRASIL. Linguagens códigos e suas tecnologias / Secretaria de Educação Básica. Orientações curriculares para o ensino médio; volume 1. Brasília: Ministério da Educação, Secretaria de Educação Básica, 2006. p. 239.

DELFINO, M. C. N. Uso de Música para o Ensino de Inglês como Inglês como Língua Estrangeira em um Ambiente Baseado em Corpus. São Paulo, 2016. Dissertação (Mestrado em Linguística Aplicada e Estudos da Linguagem) - LAEL, PUC/SP.

DELL'ISOLA, R. L. P. Gêneros textuais em livros didáticos de português língua estrangeira: o que falta? In: DIAS, R.; CRISTÓVÃO, V. L. L. O livro didático de língua estrangeira: múltiplas perspectivas. Campinas: Mercado de Letras, 2009. p.17-56.

LAJOLO, M. Livro didático: um (quase) manual do usuário. Brasília: Em aberto, ano 16, n. 69, 1996. 
MARCUSCHI, B. Redação escolar: breves notas sobre um gênero textual. In: SANTOS, C. F; MENDONÇA, M; CAVALCANTE, M. C. B. (Orgs). Diversidade textual: os gêneros textuais na sala de aula. Belo Horizonte: Autêntica, 2006. p. 59-72.

MARCUSCHI, L. A. Gêneros textuais: configuração, dinamicidade e circulação. In: KARWOSKI, A. M; GAYDECZKA, B; BRITO, K. S. (Orgs.). Gêneros textuais - reflexões e ensino. 3. ed. rev. Rio de Janeiro: Nova Fronteira, 2008. p. 15-28.

MATTOS, A. M. A. 2011. Novos Letramentos: Ensino de Língua Estrangeira e o Papel da Escola Pública no Século XXI. Revista X, 1(1):33-47.

MONTE MÓR, Walkyria. Critical Literacies, Meaning Making and New Epistemological Perspectives. Matices en Lenguas Extranjeras, [S.1.], n. 2, ene. 2008. ISSN 2011-1177. Disponível em: 〈https://revistas.unal.edu.co/index.php/male/article/view/10712/11182>. Acesso em 31 de agosto de 2016.

ORLANDO, A. F. \& FERREIRA, A. J. Do Letramento Aos Multiletramentos: Contribuições À Formação De Professores (As) Com Vistas À Questão Identitária. Travessias (UNIOESTE. Online), v. 7, p. 414-430, 2013.

PAIVA, V. L. M. O. Os desafios na produção de materiais didáticos para o ensino de línguas no ensino básico. Revista (Con) textos Linguísticos 8.10.1 (2014): 344357.

SOARES, M. Letramento e alfabetização: as muitas facetas. Revista Brasileira de Educação. Jan /Fev /Mar /Abr 2004 No 25.

TÍLIO, R. C. O papel do livro didático no ensino de língua estrangeira. Revista eletrônica do Instituto de Humanidades, v. 7, n. 26, p. 117-144, 2008.

TORTATO, C. O livro didático público de inglês: uma análise a partir das diretrizes curriculares de língua estrangeira do Estado do Paraná/ Caroline Tortato. - Curitiba, 2010. 137f. Dissertação (Mestrado em Educação) - Universidade Federal do Paraná. Disponível em: http://www.ppge.ufpr.br/teses/M10_Caroline\%20Tortato.pdf Acesso em: 22 de maio de 2016.

VERCEZE, R. Mª A. N. \& SILVINO, E. F. M. O Livro Didático e suas implicações na Prática do professor nas escolas públicas de Guajará-Mirim. Práxis Educacional Vitória da Conquista v. 4, n. 4 p. 83-102 jan. /jun. 2008. Disponível em: http://periodicos.uesb.br/index.php/praxis/article/view/328/361 Acesso em: 05 de maio de 2016.

XAVIER, A. C. S. Letramento digital e ensino. 2002. Disponível em: https://www.ufpe.br/nehte/artigos/Letramento\%20digital\%20e\%20ensino.pdf Acesso em: 01 de setembro de 2016.

XAVIER, J. P. Letramento visual crítico. Círculo Fluminense de Estudos Filológicos e Linguísticos. XIX congresso nacional de linguística e filologia. Línguas Estrangeiras e Tradução. Rio de Janeiro: CiFEFiL, 2015. Cadernos do CNLF, Vol. XIX, No 01 - Línguas Clássicas, Textos Clássicos. 
XAVIER, R. P. \& URIO, E. D. W. O professor de inglês e o livro didático: que relação é essa? Trab. Ling. Aplic, Campinas, 45(1): 29-54, Jan./Jun. 2006. Disponível em: http://www.scielo.br/pdf/tla/v45n1/a03.pdf Acesso em 01 de junho de 2016.

Tilio, R. Atividades de leitura em livros didáticos de inglês: PCN, letramento crítico e o panorama atual. Revista Brasileira de Linguística Aplicada 2(4), 997-1024. Disponível em: http://www.scielo.br/pdf/rbla/2012nahead/aop0712 Acesso em 04 de junho de 2016. 